\title{
A Study on the Application of Paraphrase Strategy in the Translation from Chinese to English
}

\author{
Yue Yan \\ Shanxi Normal University, China
}

\begin{abstract}
Paraphrase as a kind of translation strategy is often used in translation between two languages, it is also one of the ways to solve translation problems, especially the problem that two languages are not equal at word level. In this paper, the author's material is 'Farewell: Departing for "Downunder" 'from Six chapters from my life "downunder", which is written by Yang Jiang. The objective is Howard Goldblatt's English translation. The theoretical basis is Mona Baker's explanation of paraphrase from the perspective of linguistics in her book In Other Words - A coursebook on translation. The paper only studies words and expressions, it explores the reasons to cause unequal problems at word level between English and Chinese, and it mainly studies the application of paraphrase strategy from 3 aspects with quantitative and qualitative approaches: firstly, according to Mona Baker's definition about paraphrase strategy in the book of In Other Words, paraphrase strategy can be divided into "Translation by paraphrase using a related word" and "Translation by paraphrase using unrelated words", on the basis of this division, the paper counts the number of the two paraphrase strategies used by Howard Goldblatt. Then, the paper contrasts and analyzes the statistical results. At last, the author explores the reasons paraphrase strategy. And the study can improve translation.
\end{abstract}

Index Terms - paraphrase strategy, contrast and analyze, propositional meaning

\section{INTRODUCTION}

"Translation is explanation". "paraphrase" is explanatory translation, in other words, that is translation and explanation (Wang, 2015). Many western translation theorists, especially interpretive school, agree to the above opinion. Based on the above opinion, Mona Baker, a successful woman in British translation studies, regards paraphrase strategy as a way to solve the unequal problem at the word level between English and Chinese, she also divides paraphrase strategy into "Translation by paraphrase using a related word" and "Translation by paraphrase using unrelated words".

In the paper, it only studies words and expressions, it contrasts and analyzes the application of paraphrase strategy in the translation from Chinese into English on the basis of an empirical study and Mona Baker's explanation to this strategy from the perspective of linguistics in her book In Other Words, the empirical study explores the English and Chinese version of 'Farewell: Departing for "Downunder" 'from Six chapters from my life "downunder". The paper also studies the reasons and circumstances to use this strategy.

Six chapters from my life "downunder" is a memoir prose pieces work, which is written 8 years later after Yang Jiang's cadre school experience, it records Yang Jiang's detailed life in the cadre school, the book's name imitates Shen Fu's Six Chapters of a Floating Life. It has received great attention at home and abroad after its publication in 1981. "pervades one with a sense of sorrow and loss; we lament as she does but do not feel dejected, we sense her indignation at being wronged but find in this no hate or reproach. Every word is eloquent in its sincerity and truthfulness." commented by a Chinese writer. Her language is simplicity and plainness, which is known as the low-key style, the style is not only her writing style, but also the living style of her person. This book has been translated by Geremie Barne, Howard Goldblatt and Djang Chu respectively. They have strived to represent the original low-key style. Meanwhile, the one translated by Howard Goldblatt uses natural and simple language, he represents the original style better. So, the paper selects Howard Goldblatt's English translation as objective to study the application of paraphrase strategy in the translation from Chinese to English.

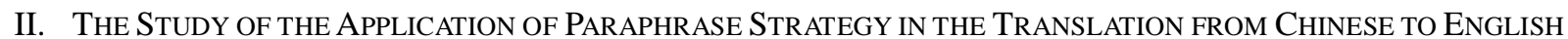

Every nation has its own life styles, values, ways of thinking, linguistic psychology, behavior standards, cultural traditions, and all of these will pose barrier and differences between English and Chinese, so, lots of words and expressions can not be translated one by one, "paraphrase" is one of the ways to remove this kind of barrier and differences (Guo, 1998). "the work of translators is to explain" is the generalization to paraphrase in the translation. the translation of paraphrase has certain freedom, there is no need to translate one word by one word, translator can do some supplement and explanation, but they can not change the original views and meaning. Paraphrase also called free translation, that is to say, translation sometimes can be explanatory translation or have certain freedom translation (Ma, 
2012). Based on Mona Baker's explanation of paraphrase, and both English and Chinese versions of 'Farewell: Departing for "Downunder" 'from Six chapters from my life "downunder", the paper studies reasons to cause unequal problems at word level and the application of paraphrase strategy in the English translation, it also analyzes the reasons to use paraphrase strategy.

\section{A. The Reasons to Cause Unequal Problems at Word Level between English and Chinese}

In this part, the author will talk about the reasons to cause unequal problems at word level between English and Chinese from 6 aspects.

(1) The differences of religious faith

Religious faith is an important part of culture, some religion's history even much more longer than certain languages, so, we can not neglect religion's impact on language. In China, Confucianism, Buddhism and Taoism form Chinese special ways of thinking and behavior. There are many Buddhism and Taoism's folktales in Chinese, for example, “borrow sth. to make a gift of it”(借花献佛), “eight immortals lead sea, each show magical power”(八仙过海, 各显神 通), “embrace Buddaha's feet and pray for help in time of emergency”(临时抱佛脚), “save one life, better than build a seven-storied pagoda”(救人一命, 胜造七级浮屠). “Buddha” and “the Eight Immortals" come from Buddhism and Taoism respectively, it's easy for Chinese people to understand, but it's hard for western people to understand if they do not know religious allusions of China.

However, as for westerners, Christianity has an great impact on their ways of thinking and behavior. They think God made everything, Bible gives them great comfort, many religious figures and allusions are included in this book. Some religious figures and allusions are familiar to westerners, but Chinese people do not know, for example, "a Solomon " refers to smart people, "as old as Methuselah" refers to longevity.

(2) The changes of history

Every nation has its own history, the Chinese nation has its own history and culture, when the history figures and events at different times are reflected on words level, some words are loaded with national culture and local colours. For example, “peach garden sworn brothers”(桃园结义), “endure present hardships to revive”(卧薪尝胆), “burning of books and burying of scholars”(焚书坑儒), “ break the caldrons and sink the boats”(破釜沉舟), all of these expressions have a corresponding touching story except for their word meaning. Such as " break the caldrons and sink the boats", it means cutting off all means of retreat to attain victory, this expression describes a story about Xiang Yu, Xiang Yu was a Chinese imperial general in the third century BC who took his troops across the Zhang River on a raid into enemy territory. To his troops' astonishment, he ordered their cooking pots crushed and their sailing ships buried. He explained that he was imposing on them a necessity for attaining victory over their opponents, what he said was truly motivating, but it was not really understood by many of his loyal soldiers as they watched their vessels go up in flames. However, the genius of Xiang Yu's conviction has been validated on the battlefield. These words can not be found in English.

(3) The different customs

Saussure had said, " the customs of a nation usually is reflected on its language, when every nation's unique social life and customs is reflected on wedding, funeral and festival customs, lexical gas will be formed". Take the marriage of China and Western countries as an example, Chinese people focus on “perfect match"(门当户对) and “the beauty and the geek"(郎才女貌); while there is “marriage of true minds" in English. Chinese people will select "auspicious occasion” (良辰吉日)when they get married, then, they will “worship to Heaven and Earth", "bow to parents” and “bow to each other”(拜天地, 拜高堂, 夫妻对拜); westerners will have a "white wedding" in the church, and “honey moon" is necessary. In addition, there are lots of lexical gaps because of festival customs and calendar, hence, a lot of words and expressions with Chinese characteristic have emerged: “the Double Ninth Festival”(重阳节), “the Dragon Boat Festival”(端午节), “Spring Equinox”(春分), “the middle ten days of a month”(中旬). Expressions such as “couplets”(对联),“set off firecrackers”(放鞭炮) and “paper-cut for window decoration”(窗花) are related to festivals, these expressions have very distinct cultural connotation, the direct corresponding expressions can not be found in other languages (Wang, 2007).

(4) The differences of life environment and experience

Natural environment and social environment form the life environment that human depend on. We human live in the same earth, we have many things in common, and languages are rooted in the survival environment of human, so, the meaning of some words and expressions is same, for example, we have the same "sun" and "moon", we live under the same sky, "with the lamb, and stopped work at sunset", "day" and "night" can find corresponding expressions in different languages.

However, every country has different geographical and life environment, so, the words and expressions are influenced by these environment. For example, rivers, lakes and mountains in China can not be found in other country, expressions with Chinese characteristic are formed. Let's look at another example, "bamboo" is China's native-born plant, there is no original words in England, “笋” in Chinese can only be translated into "bamboo-shoot".

(5) the unique ways of thinking

Different ways of thinking can also cause language differences. Different nations have different feelings towards the same things, then, these things' meaning of culture is different, the same thing may have different associative meanings 
at different cultures. For example, different nations may have different views to animals, plants, colours, numbers, their views even may be opposite. The pronunciation of "bat" is similar to "happiness" in Chinese, so, Chinese people will associate with "happiness" when they mention "bat", but "bat" is the symbol of evil in English; number 4 is the homophonic "dead" in Chinese, so, it's an ominous number, but the number do not have special cultural meaning in English. In Chinese, number 10 usually expresses deep degree, such as “the peak of perfection”(十全十美), “ten most heinous of crimes" (十恶不赦). Because of the unique ways of thinking, though many words and expressions have same meaning, their associative meaning is different, this will lead to the missing of culture-loaded words' meaning.

(6)The differences of values

The different cultural traditions make people form different values. Chinese people pay attention to manners and advocate modest, “ the ruler is the minister, the father is the son's class, the husband is the wife's class”(君为臣纲,父为 子纲, 夫为妻纲), and they form modest words and polite expressions in their communication. All of these express modest Chinese culture, they form a sharp contrast with western "freedom" and "democracy", and these words can not be found in English.

\section{B. The Classification of Paraphrase Strategy by Mona Baker}

Mona Baker divides paraphrase strategy into "Translation by paraphrase using a related word" and "Translation by paraphrase using unrelated words", and the explanation of this strategy by Mona Baker can only be used to deal with the translation at words level between two languages.

She thinks "Translation by paraphrase using a related word" can be used under two conditions: (1) when the concept expressed by the source item is lexicalized in the target language but in a different form; (2) when the frequency with which a certain form is used in the source text is significantly higher than would be natural in the target language.

In addition, if the concept expressed by the source item is not lexicalized at all in the target language, the paraphrase strategy can still be used in some contexts. Instead of a related word, the paraphrase may be based on modifying a superordinate or simply on unpacking the meaning of the source item, particularly if the item in question is semantically complex. This kind of paraphrase is called "Translation by paraphrase using unrelated words".

\section{Statistics and Contractive Analysis of Paraphrase Strategy in the English Translation}

The author does an empirical study to English and Chinese versions of 'Farewell: Departing for "Downunder" ' with quantitative and qualitative approaches, and she finds that the two types of paraphrase strategy divided by Mona Baker cover all the phenomena using paraphrase strategy in Howard Goldblatt's English translation on account of unequal problem at word level. Therefore, according to this division, the author counts the number of the two paraphrase strategies in the English translation, she also contrast and analyze the two types of paraphrase strategies.

2.3.1 The Number of the Two Types of Paraphrase Strategies in English Translation

TABLE 1

THE EXAMPLES OF THE TWO TYPES OF PARAPHRASE STRATEGIES IN THE TEXT

\begin{tabular}{|c|c|c|}
\hline $\begin{array}{l}\text { The types of } \\
\text { paraphrase strategies }\end{array}$ & $\begin{array}{l}\text { Translation by paraphrase } \\
\text { using a related word }\end{array}$ & $\begin{array}{l}\text { Translation by paraphrase } \\
\text { using a unrelated word }\end{array}$ \\
\hline $\begin{array}{l}\text { the } \\
\text { examples } \\
\text { in } \\
\text { the } \\
\text { text }\end{array}$ & $\begin{array}{l}\text { 同属---be assigned } \\
\text { 一两天---a couple of days } \\
\text { 失散---scatter to the four } \\
\text { winds } \\
\text { 好生寻找---look high and } \\
\text { low } \\
\text { 围巢---root out } \\
\text { 如火如茶---spread like } \\
\text { wildfire }\end{array}$ & $\begin{array}{l}\text { 清晨---bright and early } \\
\text { every morning } \\
\text { 下放---on one’s way down to } \\
\text { 行期---any day when we } \\
\text { would depart } \\
\text { 兵荒马乱---a time of war } \\
\text { 耐脏----not show the dirt } \\
\text { 离情---sorrows of parting } \\
\text { 左放, 右放---no matter } \\
\text { how hard I tried } \\
\text { 得空---whenever I had } \\
\text { the time/during his } \\
\text { spare time } \\
\text { 土积尘封---dirty, dusty } \\
\text { 地僻人穷---poor land } \\
\text { and even poorer people } \\
\text { 竭泽而渔---drain the } \\
\text { pond to get the fish }\end{array}$ \\
\hline In total/item & 6 & 11 \\
\hline percentage $/ \%$ & $35.29 \%$ & $64.71 \%$ \\
\hline
\end{tabular}

From the above table, we know that "Translation by paraphrase using a related word" and "Translation by paraphrase using unrelated words" are indeed used in the text of "Farewell: Departing for "Downunder", and the total number of paraphrase strategy is 17.( here, the author defines "Translation by paraphrase using a related word" as Strategy 1, defining "Translation by paraphrase using unrelated words" as Strategy 2. the following text comply with this stipulation). Here, the number of Strategy 1 is 6 , its percentage is $35.29 \%$; but the number of Strategy 2 is 11 , its 
percentage is $64.71 \%$. It's obvious that the number of Strategy 2 is more than Strategy 1.

2.3.2 The Contrastive Analysis of the Two Paraphrase Strategies

(1) The similarities of the two strategies:

“兵荒马乱”in the above table describes a scene of war, “a time of war ” indeed expresses source item's propositional meaning. But “荒”、“乱”in the expression of “兵荒马乱”are derogatory words, they show a society of turmoil and trouble, they indicate that the author of source text hates and is fed up with war. However, "a time of war" just states the facts objectively, the expression do not appraise war, so it lose its expressive meaning in comparison with the source text. What's more, “离情” is translated into "sorrows of parting" by Howard Goldblatt, the sense of sorrow usually is the main emotion when people leave each other, Howard Goldblatt's translation highlights this point, but “离情” is the emotions of farewell, this kind of emotion can be sorrow, anxious, empty or helpless, the emotion can not be confined to sorrow, so, "sorrows of parting" narrows down the emotional meaning of “离情”. Let's look at another example, the ancient meaning of “如火如茶” is strong and powerful army: the soldiers at the right part of army wear white clothes and hold white flags, such a splendid scene likes the massive white flowers of thatch; the soldiers at the left part of army wear red clothes and hold red flags, such a splendid scene likes raging flames. The expression can be used to describe fiery and busy scene later, the source item can make people associate its meaning through vivid description, although “spread like wildfire” covers up “如火如茶” ’s original meaning but loses its original associative meaning. Nevertheless, "spread like wildfire" is consistent with the expression's modern meaning, so, the source items' propositional meaning can also be expressed well.

Hence, we can draw the following conclusions: both of two strategies can achieve a high level of precision in specifying propositional meaning, but their disadvantages is that a paraphrase does not have the status of a lexical item and therefore the target language can not convey the source item's expressive, evoked or any kind of associative meaning. In addition, paraphrase itself means the loss of precision of the source items, this is another similarity of the two paraphrase strategies.

(2) The differences of the two strategies:

The above table tells us that Strategy 1 usually do not let the target text's length have obvious changes comparing to the source text. However, because the target items is not lexicalized in Strategy 2, and it involves filling a one-item slot with an explanation consisting of several items, so it will visibly enlarge the target text, and the target text sometimes will be cumbersome and awkward by this way. Of course, there exists some exceptions: “失散” is translated into “scatter to the four winds" by Strategy 1, the target text is enlarged; meanwhile, “土积尘封” is translated into “dirty, dusty" by Strategy 2, the target text is shorten, but it's rare to happen.

\section{The Reasons to Use Paraphrase Strategy}

According to Mona Baker, any kind of paraphrase strategies aims to solve the unequal problems at word level between English and Chinese, translators have no option but to do this. So the reason to use paraphrase strategy is there are unequal problems at word level between two languages.

Meanwhile, on the basis of Mona Baker's theory and table1, we can have the following statements: When the concept expressed by the source item is lexicalized in the target language, but the corresponding lexicalized items in the target language is unnatural when they are used (because their frequency of use is significantly lower than the source text), or they are in a different form, then, Strategy 1 is used. However, when the lexicalized items do not exist in the target language, Strategy 1 can not be used, but the paraphrase can still be used by modifying a superordinate or simply on unpacking the meaning of the source item, particularly if the item in question is semantically complex, that's Strategy 2.

\section{CONClusions}

According to the statistics, we are sure that paraphrase strategy can be divided into "Translation by paraphrase using a related word" and "Translation by paraphrase using unrelated words", and table 1 tells us that "Translation by paraphrase using unrelated words" is more than "Translation by paraphrase using a related word". But the number of the two paraphrase strategies is not representative, because different style leads to different numbers. Six chapters from my life "downunder" is a memoir prose pieces work, the results of analysis only show the use of paraphrase strategy, they can not show that all the articles use this strategy, likewise, we can also say that "Translation by paraphrase using a related word" is always less than "Translation by paraphrase using unrelated words".

"Paraphrase" is explanatory translation, paraphrase strategy is used to solve the unequal problems at word level. The main advantage of the two types of paraphrase strategies is that both of them can achieve a high level of precision in specifying propositional meaning, but their disadvantages is that a paraphrase does not have the status of a lexical item and therefore the target language can not convey the source items' expressive, evoked or any kind of associative meaning, because expressive and evoked meaning are associated only with stable lexical items which have a history of recurrence in specific context. A second disadvantage of paraphrase strategy is the loss of precision of the source items. What's more, in most cases, "Translation by paraphrase using a related word" usually do not let the target text's length have obvious changes comparing to the source text, however, "Translation by paraphrase using unrelated words" will 
visibly enlarge the translated text. In addition, the paper shows us that the two strategies aim to solve the unequal problems at the word level in translation, though they have different ways to achieve it. And we clearly know that paraphrase strategy plays an important role in the translation from Chinese into English, and this study can improve translation.

\section{REFERENCES}

[1] Guo Aixian. (1998). Lexical Gaps and Their Translatability. Journal of PLA University of Foreign Languages, 5, 42-43.

[2] Mona Baker. (2011). In Other Words: A coursebook on translation. London and New York: Taylor and e-Library.

[3] Ma Jingqiu. (2012). The Translation of Literal Translation, Paraphrase and Imitation. Overseas English, 23, 148-151.

[4] Wang Yanjun. (2007). Talk about the Teaching Materials Writing and Teaching Thought of the "Chinese folk" course when Chinese is a foreign language. Journal of College of Chinese Language and Culture of Jinan University, 1, 32-36.

[5] Wang Xiangyuan. (2015). "Transfer Translation", "Paraphrase", and "Creative Translation" to replace "Literal Translation", and "Liberal Translation". Journal of Shanghai Normal University, 5, 132-142.

[6] Yang Jiang. (2015). Six chapters from my life “downunder”. Shanghai: SDX Joint Publishing Company.

Yue Yan was born in Lin Fen, China in 1993. Now, she is a linguistic postgraduate, she studies at Shanxi Normal University in Shanxi province, this is her second year at this University.

She has been a teacher at a senior high school in 2015. She is currently a postgraduate at Shanxi Normal University, her research interests include translation and language learning strategies. 